\title{
Sleeping Patterns of Thai Airways Flight Attendants during the Off-Duty Period Using a Photovoice Technique ${ }^{+}$
}

\author{
Vongsa Laovoravit 1,*, Krit Pongpirul ${ }^{2}$, Watana Manon ${ }^{1}$, Nirund Thiptananont ${ }^{1}$ and \\ Aurawan Imsombut ${ }^{3}$ \\ 1 College of Aviation Development and Training, Dhurakij Pundit University, 10210 Nonthaburi, Thailand; \\ watana.man@dpu.ac.th (W.M.); nirund.thi@dpu.ac.th (N.T.) \\ 2 Department of Preventive and Social Medicine, Faculty of Medicine, Chulalongkorn University, \\ 10330 Bangkok, Thailand; doctorktrit@gmail.com \\ 3 College of Creative Design and Entertainment Technology, Dhurakij Pundit University, \\ 10210 Nonthaburi, Thailand; aurawan.ims@dpu.ac.th \\ * Correspondence: vongsa.lao@dpu.ac.th; Tel.: +66(81)-621-7390 \\ + Presented at the Innovation Aviation \& Aerospace Industry-International Conference 2020 (IAAI 2020), \\ Chumphon, Thailand, 13-17 January 2020.
}

Published: 30 December 2019

\begin{abstract}
A flight attendant has an irregular working schedule that requires to travel across different time zones, which affects their circadian rhythms and challenges the body to resynchronize with the local environment of the destination. Since human capabilities are considered critical factors that have an impact on safety in aviation, an accumulation of sleep debt over time can result in (1) impaired performance from fatigue and decreased alertness (2) increase the likelihood of forgetfulness, which can lead to the adverse in-flight operation safety. This study aimed to examine the sleep quality and to explore the sleep patterns of Thai Airways flight attendants. The PSQI (Pittsburgh Sleep Quality Index), a subjective measure of sleep, was adopted to recruit flight attendants with sleep difficulty. Two male and two female flight attendants who had the highest PSQI scores at 18, 18, 16, 15 of the total score 21 were selected, whereas lower scores under 5 denote a healthier sleep quality. Besides, Fitbit, an external sleep tracker device, was worn on individuals' wrist for seven nights. Fitbit application on their smartphone created seven photos of each flight attendant, of which some show unusual sleep patterns that might associate with their working lifestyle and sleep habits.
\end{abstract}

Keywords: flight attendant; circadian rhythm; sleep quality; sleep pattern

\section{Introduction}

It appears that the health consequences of a flight attendant job have not been intensively studied, despite human capabilities are considered critical factors that have an impact on maintaining safety in aviation as an accumulation of sleep debt over time can result in performance-impairing fatigue, decreased alertness, increase the likelihood of forgetfulness, which can lead to the adverse in-flight operation safety. Apparently, a unique occupational lifestyle of a flight attendant demands the job to become more stringent than others in terms of job conditions that require to travel across different time zones, shifting continuously back and forth between eastward and westward away from the domicile time zone very rapidly and frequently due to irregular working schedule affects not only to the circadian rhythms, a light-related biological clock in the brain that is designed to 
follow the flow of sunlight [1], but also challenges the physical to resynchronize with the local environment of the destination concerning light-darkness cycle. According to the repair and restoration theory of sleep, sleeping is essential for revitalizing and restoring the physiological processes that keep the body and mind healthy and properly functioning [2-4]. Sleep is a necessary condition in which the body intentionally produces for the purposes that scientists believe are beneficial for the human body. Nevertheless, to feel fully rested, a healthier sleep should not only be indicated by the quantity, which refers to the total number of hours slept during the night but also should be measured by the quality of sleep that based on how well we sleep each night as the more time we spent in deep and REM sleep [5], the better sleep quality and a restful night we got.

\section{Definitions of Key Terms}

The PSQI (Pittsburgh Sleep Quality Index) was developed in 1988 by Daniel J. Buysse, a researcher at The University of Pittsburgh. It is a self-report questionnaire to assess sleep quality over a one-month time interval. It consists of 7 components, 19 individual items [6]. Each item is weighted on a 0-3 interval scale, providing one global score rating from 0-21 where lower the score under 5 denotes a healthier sleep quality while higher the score, on the other hand, indicates an unhealthy sleep quality.

Circadian rhythms: A 24-h biological clock that is ticking internally in the brain create the circadian rhythm, and it cycles between sleepiness and alertness at the regular intervals. It is also known as the sleep/wake cycle, which relies on the environmental cues of daylight and darkness [7].

Sleep stages: Five stages of sleep rotate between non-rapid eye movement (NREM) and rapid eye movement (REM). Sleep stages 1, 2, and REM consist of light sleep, while 3 and 4 comprise deep sleep. Each night, the body typically goes through several sleep cycles alternately that last on an average of $90 \mathrm{~min}$ interval [8,9].

Off-duty period: Defines as a continuous period after duty, during which time crewmembers are free of all duties. In general, the longer a crewmember is away from the home-base/domicile time zone, the more recovery time is needed for readjustment to home-base/domicile time.

\section{Objectives}

The objectives of this research aimed to:

1. Examine the sleep quality of Thai Airways flight attendants who experienced sleep problems such as difficulty falling asleep and excessive daytime sleepiness.

2. Explore the sleep patterns of Thai Airways flight attendants, which related to the timing, amount, and quality of sleep as a result of irregular sleep patterns.

\section{Materials and Methods}

\subsection{Target Participants}

This qualitative research was conducted on Thai Airways flight attendants using a purposive sampling technique. Twelve anonymous male and female flight attendants ages $32-42$ who have been working for 10-20 years were asked to recall their sleep habits over the past month.

\subsection{Instruments}

The PSQI measuring instrument was adopted to use as a tool to recruit flight attendants who experience trouble with sleep disorders, sleep deprivation, or subjective day time sleepiness. The PSQI has been standardized and widely used in many sleep quality studies which has showed reliability and validity for both healthy and clinical groups with mental and physical health problems [10-12], in different age groups, from youth to elderly people [13,14], with risk-taking behaviors, including drug use and drowsy driving in young adults $[15,16]$, and in different cultural contexts [17-21]. Besides, Fitbit, an external sleep tracker device based on a combination of movement and heart-rate patterns, was worn on individuals' wrist for seven nights to estimate sleep stages. 


\subsection{Methods}

Participants were asked to answer 19 individual questions related to seven principal components, namely sleep quality, sleep latency, sleep duration, habitual sleep efficiency, sleep disturbance, use of sleep medication, and daytime dysfunction. Fitbit application on applicants' smartphone created seven photos of each flight attendant that showed the analyzed sleep patterns, which refers to time to bed, time to rise, sleep cycle, and duration of a restful night.

\section{Results and Discussion}

\subsection{Results}

Two male and two female flight attendants who had the highest PSQI scores at 18, 18, 16, 15, as a result, shown in Tables 1-8, of the total score 21, were eventually recruited to further investigate in this study from June to July 2019.

Table 1. Component 1 of the PSQI on the 4 flight attendants.

\begin{tabular}{|c|c|c|c|c|}
\hline \multirow{2}{*}{ Subjective Sleep Quality } & \multicolumn{4}{|c|}{ Self-Report on COMPONENT 1} \\
\hline & Male 1st & Male 2nd & Female 1st & Female $^{2 n d}$ \\
\hline * Rating of overall sleep quality & & & & \\
\hline $\begin{array}{l}\text { Note: (Very good (0), Fairly good (1), } \\
\text { Fair bad (2), Very bad (3)). }\end{array}$ & 3 & 3 & 3 & 3 \\
\hline
\end{tabular}

Table 2. Component 2 of the PSQI on the 4 flight attendants.

\begin{tabular}{|c|c|c|c|c|}
\hline \multirow{2}{*}{ Sleep Latency } & \multicolumn{4}{|c|}{ Self-Report on COMPONENT 2} \\
\hline & Male 1st & Male $^{2 n d}$ & Female 1st & Female 2nd \\
\hline * The time that takes to fall asleep & & & & \\
\hline $\begin{array}{l}\text { Note: }(\leq 15 \min =(0), 16-30 \mathrm{~min}=(1), 31-60 \mathrm{~min}= \\
(2),>60 \mathrm{~min}=(3))\end{array}$ & 2 & 2 & 3 & 3 \\
\hline $\begin{array}{l}\text { The Frequency of trouble falling asleep } \\
\text { Note: (Not during the past month (0), Less than } \\
\text { once a week (1), Once or twice a week (2), Three } \\
\text { or more times a week (3)) }\end{array}$ & 3 & 3 & 3 & 3 \\
\hline SUM & 5 & 5 & 6 & 6 \\
\hline $\begin{array}{l}\text { Note: (if SUM is equal } 0=(0) ; 1-2=(1) ; 3-4=(2) \\
5-6=(3))\end{array}$ & 3 & 3 & 3 & 3 \\
\hline
\end{tabular}

Table 3. Component 3 of the PSQI on the 4 flight attendants.

\begin{tabular}{|c|c|c|c|c|}
\hline \multirow{2}{*}{ Sleep Duration } & \multicolumn{4}{|c|}{ Self-Report on Component 3} \\
\hline & Male 1st & Male 2nd & Female 1st & Female ${ }^{2 n d}$ \\
\hline $\begin{array}{l}\text { * Hours of actual sleep per night } \\
\text { Note: }(>7=(0), 6-7=(1), 5-6=(2),<5=(3))\end{array}$ & 3 & 2 & 2 & 0 \\
\hline
\end{tabular}

Table 4. Component 4 of the PSQI on the 4 flight attendants.

\begin{tabular}{|c|c|c|c|c|}
\hline \multirow{2}{*}{ Habitual Sleep Efficiency } & \multicolumn{4}{|c|}{ Self-Report on COMPONENT 4} \\
\hline & Male 1st & Male $^{2 n d}$ & Female 1st & Female $^{2 n d}$ \\
\hline * Percentage of Habitual sleep efficiency & & & & \\
\hline $\begin{array}{l}\text { Note: }(>85 \%=(0), 75-84 \%=(1), 65-74 \%= \\
(2),<65 \%=(3))\end{array}$ & 1 & 1 & 0 & 1 \\
\hline
\end{tabular}


Table 5. Component 5 of the PSQI on the 4 flight attendants.

\begin{tabular}{|c|c|c|c|c|}
\hline \multirow{2}{*}{ Sleep Disturbances } & \multicolumn{4}{|c|}{ Self-Report on COMPONENT 5} \\
\hline & Male 1st & Male 2nd & Female 1st & Female 2nd \\
\hline \multicolumn{5}{|l|}{$\begin{array}{l}\text { * Frequency of sleep disturbances due to following reasons: } \\
\text { Note: (Not during the past month (0), Less than once a week (1), } \\
\text { Once or twice a week (2), Three or more times a week (3)) }\end{array}$} \\
\hline - $\quad$ wake up in the middle of the night or early morning & 3 & 3 & 3 & 3 \\
\hline - $\quad$ have to get up to use the toilet & 3 & 3 & 3 & 3 \\
\hline - $\quad$ cannot breathe comfortably & 3 & 3 & 0 & 1 \\
\hline - $\quad$ cough or snore loudly & 3 & 3 & 2 & 2 \\
\hline - feel too cold & 3 & 2 & 3 & 3 \\
\hline - $\quad$ feel too hot & 2 & 2 & 3 & 3 \\
\hline - $\quad$ had bad dreams & 1 & 1 & 1 & 1 \\
\hline - $\quad$ have pain & 3 & 3 & 3 & 3 \\
\hline SUM & 21 & 20 & 18 & 19 \\
\hline Note: (if SUM is equal $0=(0) ; 1-9=(1) ; 10-18=(2) ; 19-27=(3))$ & 3 & 3 & 2 & 3 \\
\hline
\end{tabular}

Table 6. Component 6 of the PSQI on 4 the flight attendants.

\begin{tabular}{|c|c|c|c|c|}
\hline \multirow{2}{*}{ Use of Sleeping Medication } & \multicolumn{4}{|c|}{ Self-Report on Component 5} \\
\hline & Male 1st & Male 2nd & Female $^{1 s t}$ & Female $^{2 \text { nd }}$ \\
\hline * Frequency use of sleep medication to assist sleep & & & & \\
\hline $\begin{array}{l}\text { Note: (Not during the past month }(0) \text {, Less than once a } \\
\text { week (1), Once or twice a week (2), Three or more times } \\
\text { a week (3)) }\end{array}$ & 2 & 3 & 2 & 3 \\
\hline
\end{tabular}

Table 7. Component 7 of the PSQI on the 4 flight attendants.

\begin{tabular}{|c|c|c|c|c|}
\hline \multirow{2}{*}{ Daytime Dysfunction } & \multicolumn{4}{|c|}{ Self-Report on Component 6} \\
\hline & Male $^{1 s t}$ & Male 2nd & Female $^{1 \text { st }}$ & Female $^{2 n d}$ \\
\hline $\begin{array}{l}\text { * Trouble staying awake while driving, eating meals or } \\
\text { engaging in social activity } \\
\text { Note: (Never }(0) \text {, Once or twice (1), Once or twice each } \\
\text { week (2), Three or more times each week (3)) }\end{array}$ & 3 & 3 & 3 & 2 \\
\hline $\begin{array}{l}\text { * Problem to keep up enough enthusiasm to get things } \\
\text { done } \\
\text { Note: (No problem (0), Very slightly (1), Somewhat of a } \\
\text { problem (2), Huge problem (3)) }\end{array}$ & 3 & 3 & 2 & 3 \\
\hline SUM & 6 & 6 & 5 & 5 \\
\hline Note: (if SUM is equal $0=(0) ; 1-2=(1) ; 3-4=(2) ; 5-6=(3)$ ) & 3 & 3 & 3 & 3 \\
\hline
\end{tabular}

Table 8. Summary of the PSQI-seven main components on the 4 flight attendants.

\begin{tabular}{|c|c|c|c|c|}
\hline & \multicolumn{4}{|c|}{ Global PSQI Scores } \\
\hline & Male 1st & Male $^{2 n d}$ & Female ${ }^{1 s t}$ & Female $^{2 n d}$ \\
\hline Component 1: Subjective sleep quality & 3 & 3 & 3 & 3 \\
\hline Component 2: Sleep latency & 3 & 3 & 3 & 3 \\
\hline Component 3: Sleep duration & 3 & 2 & 2 & 0 \\
\hline Component 4: Habitual sleep efficiency & 1 & 1 & 0 & 1 \\
\hline Component 5: Sleep disturbances & 3 & 3 & 2 & 3 \\
\hline Component 6: Use of sleeping medication & 2 & 3 & 2 & 3 \\
\hline Component 7: Daytime dysfunction & 3 & 3 & 3 & 3 \\
\hline SUM & 18 & 18 & 15 & 16 \\
\hline
\end{tabular}

Remark:

- A score based on a Likert scale of $0-3$, where a score of " 0 " indicates no difficulty, while a score of " 3 " indicates severe difficulty. 
- A global PSQI score with a range of 0-21 points, if SUM is equal 0 indicates no difficulty and 21 indicates severe difficulty in all areas.

- A global SUM of 5 or higher indicates a poor sleep quality, whereas lower scores under 5 denote a healthier sleep quality [6].

The results from the Fitbit application showed each participant's sleep record during their authentic bedtimes in terms of time to bed, time to wake up, and the duration of a restful night at a destination. Besides, the comparison of UTC, which refers to Coordinated Universal Time, between the local time at destinations with the home base times in Bangkok present in Tables 9-12 shows the difference of bedtimes at difference schedules.

Table 9. Analyzed data from the Fitbit application of the 1st Male Flight Attendant.

\begin{tabular}{|c|c|c|c|c|}
\hline \multirow[b]{2}{*}{ Date } & \multicolumn{3}{|c|}{ Comparative Bedtimes at the Destinations with the Home Base Times in Bangkok } & \multirow{2}{*}{$\begin{array}{c}\text { Sleep } \\
\text { Duration }\end{array}$} \\
\hline & Destination & Bedtimes at Destination & $\begin{array}{c}\text { Home Base Times } \\
\text { (Bangkok) }\end{array}$ & \\
\hline 17 June 2019 & $\begin{array}{c}\text { Zurich, } \\
\text { Switzerland }\end{array}$ & 14.19-17.59 (UTC + 1) & 19.19-22. 59 (UTC + 6) & $3.28 \mathrm{~h}$ \\
\hline 18 June 2019 & $\begin{array}{l}\text { Zurich, } \\
\text { Switzerland }\end{array}$ & 21.55-03.42 (UTC + 1) & 02.55-08.42 (UTC + 6) + 1 day & $4.39 \mathrm{~h}$ \\
\hline 20 June 2019 & Bangkok, Thailand & $00.00-06.23(\mathrm{UTC}+6)+1$ day & $00.00-06.23(\mathrm{UTC}+6)+1$ day & $5.26 \mathrm{~h}$ \\
\hline 22 June 2019 & Guangzhou, China & $00.22-06.33(\mathrm{UTC}+7)+1$ day & 23.22-05.33 (UTC + 6) & $5.22 \mathrm{~h}$ \\
\hline 26 June 2019 & Taipei, Taiwan & $00.08-04.54(\mathrm{UTC}+7)+1$ day & 23.08-03.54 (UTC + 6) & $3.59 \mathrm{~h}$ \\
\hline 28 June 2019 & Krabi, Thailand & $00.32-04.15(\mathrm{UTC}+6)+1$ day & $00.32-04.15(\mathrm{UTC}+6)+1$ day & $3.07 \mathrm{~h}$ \\
\hline 29 June 2019 & Nagoya, Japan & $00.00-05.14(\mathrm{UTC}+8)+1$ day & $22.00-03.14(\mathrm{UTC}+6)$ & $4.33 \mathrm{~h}$ \\
\hline
\end{tabular}

Table 10. Analyzed data from the Fitbit application of the 2nd Male Flight Attendant.

\begin{tabular}{|c|c|c|c|c|}
\hline \multirow{2}{*}{ Date } & \multicolumn{3}{|c|}{ Comparative Bedtimes at the Destinations with the Home Base Times in Bangkok } & \multirow{2}{*}{$\begin{array}{c}\text { Sleep } \\
\text { Duration }\end{array}$} \\
\hline & Destination & Bedtimes at Destination & Home base Times (Bangkok) & \\
\hline 01 July 2019 & Nagoya, Japan & $04.28-07.59(\mathrm{UTC}+8)$ & $02.28-05.59(\mathrm{UTC}+6)$ & $3.04 \mathrm{~h}$ \\
\hline 02 July 2019 & Shanghai, China & 23.37-05.30 (UTC + 7) & 22.37-04.30 (UTC + 6) & $4.53 \mathrm{~h}$ \\
\hline 06 July 2019 & Milan, Italy & $02.14-11.07(\mathrm{UTC}+1)+1$ day & 07.14-16.07 (UTC + 6) + 1 day & $7.43 \mathrm{~h}$ \\
\hline 08 July 2019 & Bangkok, Thailand & $04.28-07.48(\mathrm{UTC}+6)+1$ day & $04.28-07.48(\mathrm{UTC}+6)+1$ day & $2.46 \mathrm{~h}$ \\
\hline 11 July 2019 & Bangkok, Thailand & 01.14-07.11 (UTC + 6) + 1 day & 01.14-07.11 (UTC + 6) + 1 day & $5.16 \mathrm{~h}$ \\
\hline 13 July 2019 & Hokkaido, Japan & 01.12-05.24 (UTC + 8) + 1 day & 23.12-03.24 (UTC + 6) & $3.37 \mathrm{~h}$ \\
\hline 19 July 2019 & Shanghai, China & $00.13-07.46(\mathrm{UTC}+7)+1$ day & 23.13-06.46 (UTC + 6) & $6.21 \mathrm{~h}$ \\
\hline
\end{tabular}

Table 11. Analyzed data from the Fitbit application of the 1st Female Flight Attendant.

\begin{tabular}{|c|c|c|c|c|}
\hline \multirow{2}{*}{ Date } & \multicolumn{3}{|c|}{ Comparative Bedtimes at the Destinations with the Home Base Times in Bangkok } & \multirow{2}{*}{$\begin{array}{c}\text { Sleep } \\
\text { Duration }\end{array}$} \\
\hline & Destination & Bedtimes at Destination & Home base Times (Bangkok) & \\
\hline 01 July 2019 & Copenhagen, Denmark & $18.41-04.20(\mathrm{UTC}+1)$ & $23.41-09.20(\mathrm{UTC}+6)$ & $7.58 \mathrm{~h}$ \\
\hline 04 July 2019 & Sydney, Australia & 22.33-06.31 (UTC + 9) & 19.33-03.31 (UTC + 6) & $6.55 \mathrm{~h}$ \\
\hline 05 July 2019 & Bangkok, Thailand & 20.13-05.51 (UTC + 6) & 20.13-05.51 (UTC + 6) & $7.42 \mathrm{~h}$ \\
\hline 07 July 2019 & Saigon, Vietnam & 20.46-04.48 (UTC + 6) & 20.46-04.48 (UTC + 6) & $7.17 \mathrm{~h}$ \\
\hline 08 July 2019 & Bangkok, Thailand & $20.03-06.44(\mathrm{UTC}+6)$ & $20.03-06.44(\mathrm{UTC}+6)$ & $9.02 \mathrm{~h}$ \\
\hline 09 July 2019 & Hanoi, Vietnam & 20.59-04.56 (UTC + 6) & 20.59-04.56 (UTC + 6) & $6.53 \mathrm{~h}$ \\
\hline 11 July 2019 & Muscat, Oman & 21.49-07.14 (UTC + 3) & 00.49-10.14 (UTC + 6) + 1 day & $8.23 \mathrm{~h}$ \\
\hline
\end{tabular}

Table 12. Analyzed data from the Fitbit application of the 2nd Female Flight Attendant.

\begin{tabular}{|c|c|c|c|c|}
\hline \multirow{2}{*}{ Date } & \multicolumn{3}{|c|}{ Comparative Bedtimes at the Destinations with the Home Base Times in Bangkok } & \multirow{2}{*}{$\begin{array}{c}\text { Sleep } \\
\text { Duration }\end{array}$} \\
\hline & Destination & Bedtimes at Destination & Home base Times (Bangkok) & \\
\hline 14 July 2019 & Chiang Mai, Thailand & $20.18-05.53(\mathrm{UTC}+6)$ & $20.18-05.53(\mathrm{UTC}+6)$ & $7.42 \mathrm{~h}$ \\
\hline 15 July 2019 & Phuket, Thailand & $20.56-$ & $20.56-06.24($ & $7.58 \mathrm{~h}$ \\
\hline 16 July 2019 & Bangkok, Thailand & 20.34-05.11 (UTC + 6) & 20.34-05.11 (UTC + 6) & $7.18 \mathrm{~h}$ \\
\hline 17 July 2019 & Dubai, UAE & 21.39-07.05 (UTC + 3) & 00.39-10.05 (UTC + 6) + 1 day & $7.26 \mathrm{~h}$ \\
\hline 18 July 2019 & Dubai, UAE & 21.24-06.15 (UTC + 3) & 00.24-09.15 (UTC + 6) + 1 day & $7.41 \mathrm{~h}$ \\
\hline 21 July 2019 & Bangkok, Thailand & 21.16-03.42 (UTC + 6) & 21.16-03.42 (UTC + 6) & $5.09 \mathrm{~h}$ \\
\hline 22 July 2019 & Taipei, Taiwan & 20.29-03.43 (UTC + 7) & $19.29-02.43(\mathrm{UTC}+6)$ & $6.18 \mathrm{~h}$ \\
\hline
\end{tabular}


Moreover, the sleep patterns of each participant tracked by the Fitbit application on their mobile phones show the details of sleep cycles and the duration of each sleep stage. It is interestingly to notice some unusual sleep patterns that might somewhat associate with their working lifestyle and sleep habits, as shown in Appendix A, Figures A1-A28.

\subsection{Discussion}

Health consequences of a flight attendant become a topical issue of medical fitness, with a focus on fatigue as an occupational health and safety hazard [22]. Chronic insufficient sleep due to sleeping less than recommended ( $7 \mathrm{~h}$ per day) results in a "sleep debt" that gradually accrues over period of time [23-27], resulting in a higher tendency to fall asleep unintentionally [28-30], and is associated with more drowsiness while working extended duty period and during their commute home [31,32]. Hence, future research is needed to find out suitable treatments that help promote and improve the quality of life of a flight attendant for the benefits of (1) alleviating risk factors, which have somewhat associated with mistakes caused by human error (2) to raise the awareness of cumulative sleep debt caused by unusual sleep habits due to working lifestyle, which may affect the impaired performance of a flight attendant that leads to the safety of in-flight operations and the accountability of an airline.

\section{Conclusions}

Since Aviation Industry recognizes that fatigue was associated with numerous accidents, incidents, and near misses over the past years and is a continuing problem facing crews flying aircraft of all sizes [33]. Cumulative sleep loss of a flight attendant due to the circadian rhythms disruption is critical when the body is challenged to resynchronize with the local environment of the destination when operating irregular working schedules. The light-dark cycle has a significant impact on a flight attendant's circadian rhythms that can speed up, slow down, or reset the brain to release melatonin at the wrong time [34]. This study helps to explore the sleep patterns and examine the sleep quality of Thai Airways flight attendants that might associate with a variety of health issues, which affect their quality of life caused by sleep disruptions and irregular sleep patterns. During sleep, the body is working to maintain physical health and support healthy brain function. Deep sleep is vital for the human body process such as cell regeneration and growth hormone secretion [35,36], while a poorquality sleep due to circadian rhythms disruption may result in sleep disorders such as difficulty falling asleep, sleep disturbances, and excessive daytime sleepiness, which can negatively affect overall physical functions and adversely influence mental conditions that include depression. Persistent sleeplessness of a flight attendant may also influence other human factors issues caused by the deteriorated of brain functions that account for impaired perception, difficulties in keeping concentration, vision disturbances, a poor memorizing, slower reaction which affects to lower capabilities and efficiency of job performance that consequently lead to the increased number of mistakes as several studies have documented the precise consequences of insufficient and inconsistent sleep [33-39]. Therefore, a good night's rest is not only essential for the well-being of Thai Airways flight attendants but also has a significant association with their mental health in various aspects such as mood, memory, and cognitive performance.

Author Contributions: K.P. and W.M. initiated the idea and provided overall administration and supervision. V.L. and N.T. reviewed the measurement tool, interviewed participants, and data collection. A.I. provided the data analysis tool. V.L., N.T., and A.I. analyzed and interpreted the data. V.L. wrote an initial draft of the article and prepared the manuscript. All authors reviewed and provided suggestions. V.L. wrote the final manuscript. All authors read and approved the final manuscript of the version to be published.

Funding: This research received funding from Dhurakij Pundit University.

Acknowledgments: The conduct of this research would not be possible without excellent cooperation from all Thai Airways flight attendants, who agreed to participate and provided beneficial information, sound opinions, and valuable assistance at their best through the period of this study.

Conflicts of Interest: The authors declare no conflict of interest. 


\section{Appendix A. The Sleep Patterns of Each Participant Tracked by the Fitbit Application}

Figures A1-A7 show sleep pattern of the 1st Male Flight Attendant at various sleep ports.

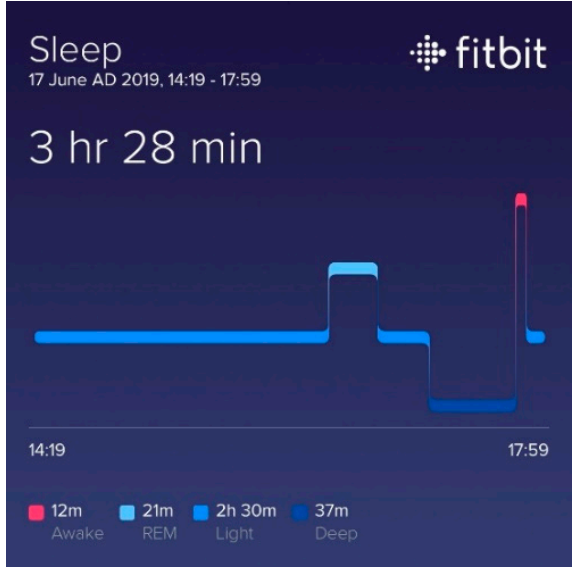

Figure A1. Zurich, Switzerland.

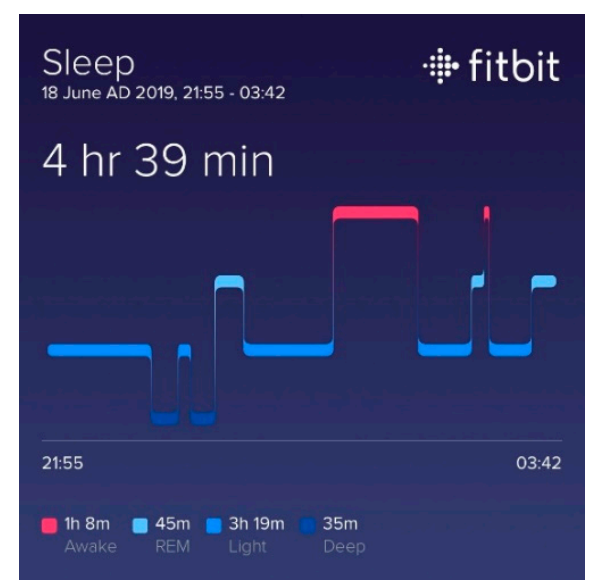

Figure A2. ZURICH, SWITZERLAND.

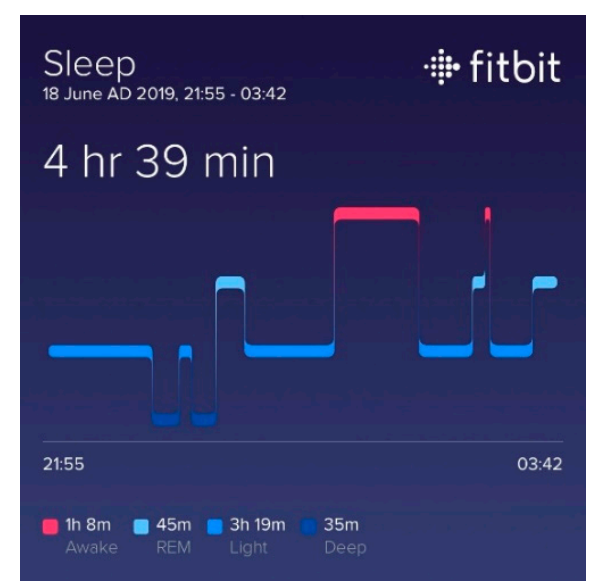

Figure A3. Bangkok, Thailand. 


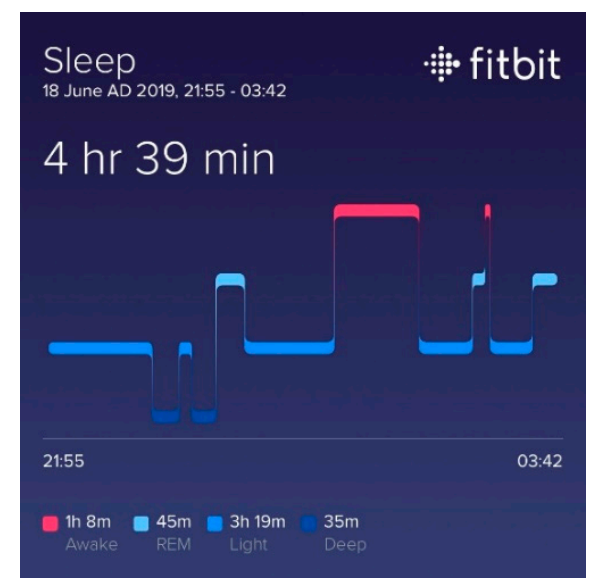

Figure A4. Guangzhou, China.

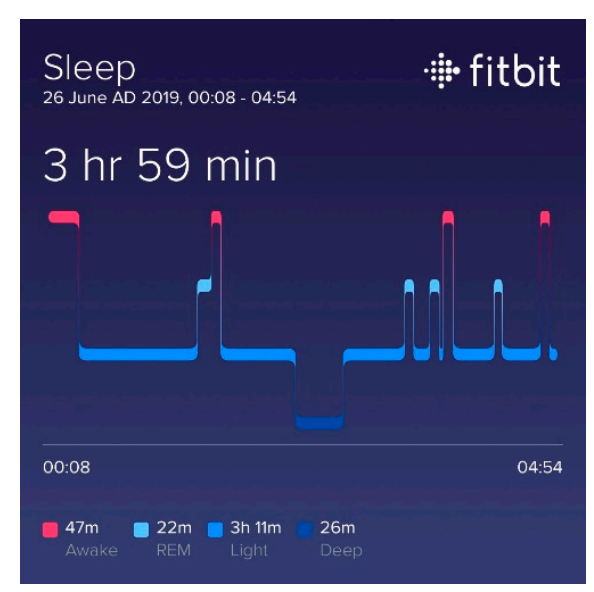

Figure A5. Taipei, Taiwan.

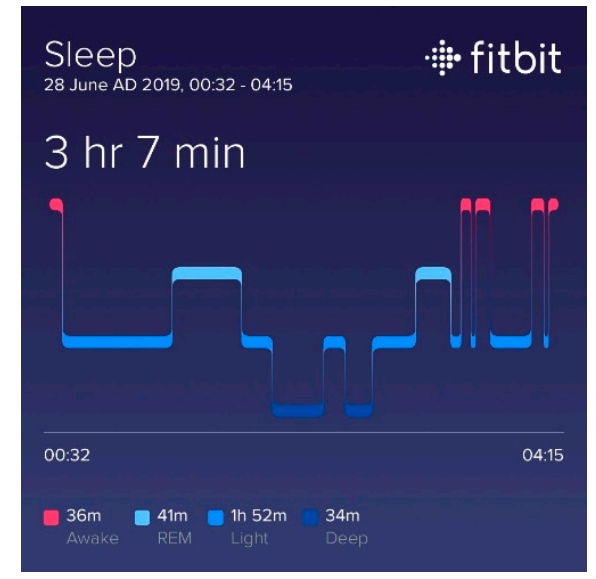

Figure A6. Krabi, Thailand. 


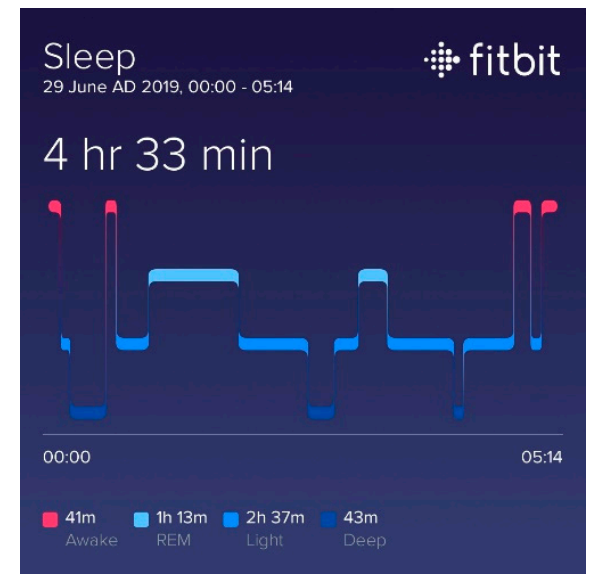

Figure A7. Nagoya, Japan.

Figures A8-A14 show sleep pattern of the 2nd Male Flight Attendant at various sleep ports.

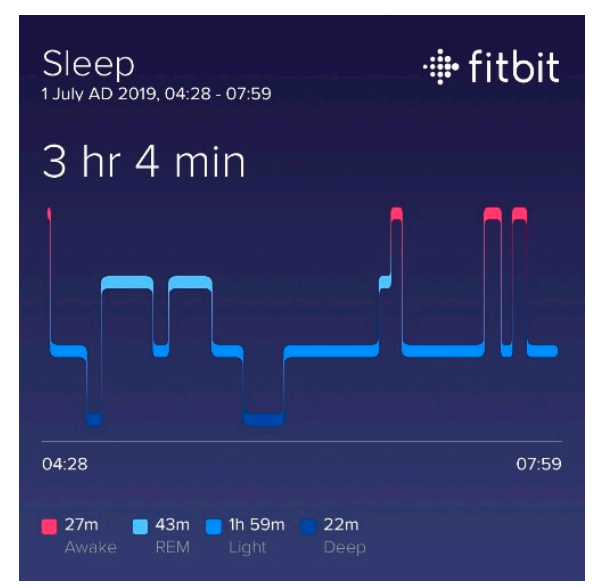

Figure A8. Nagoya, Japan.

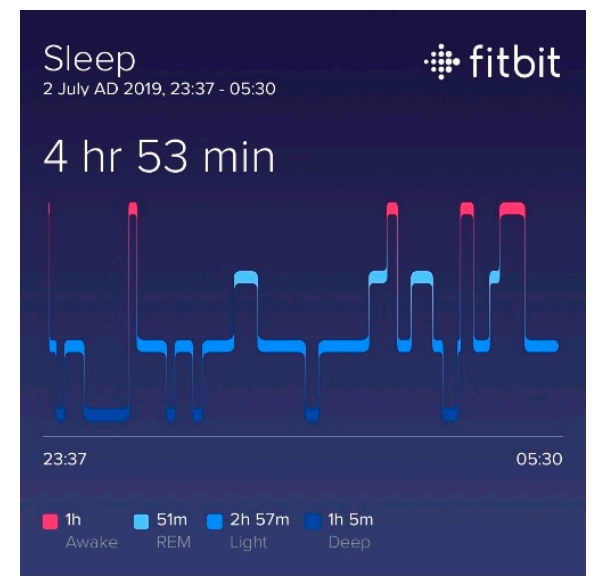

Figure A9. Shanghai, China. 


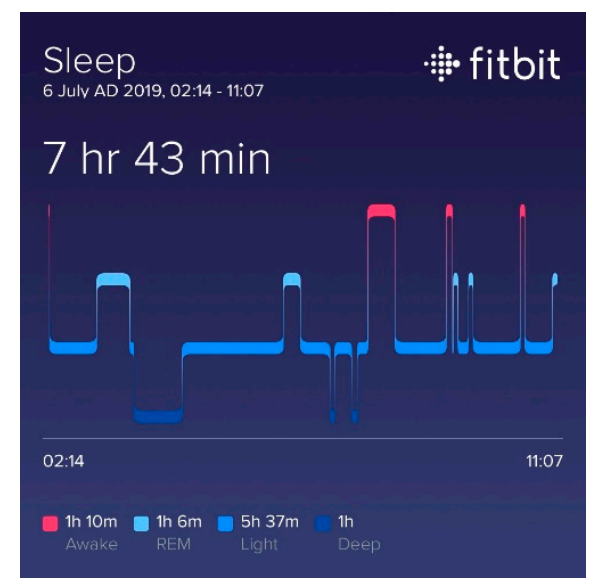

Figure A10. Milan, Italy.

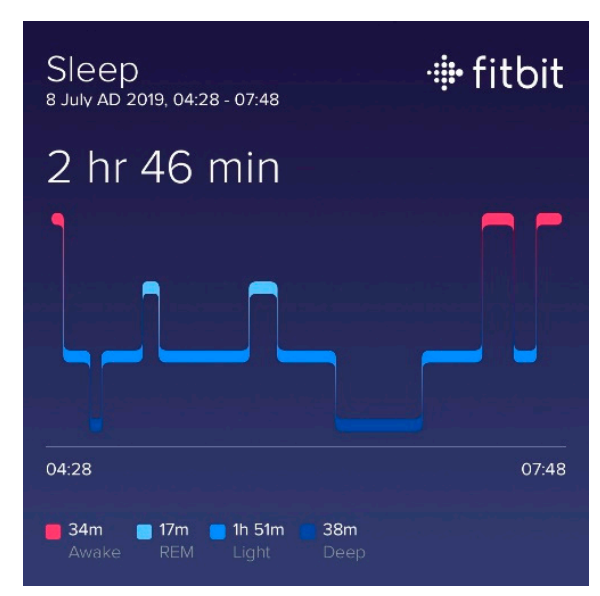

Figure A11. Bangkok, Thailand.

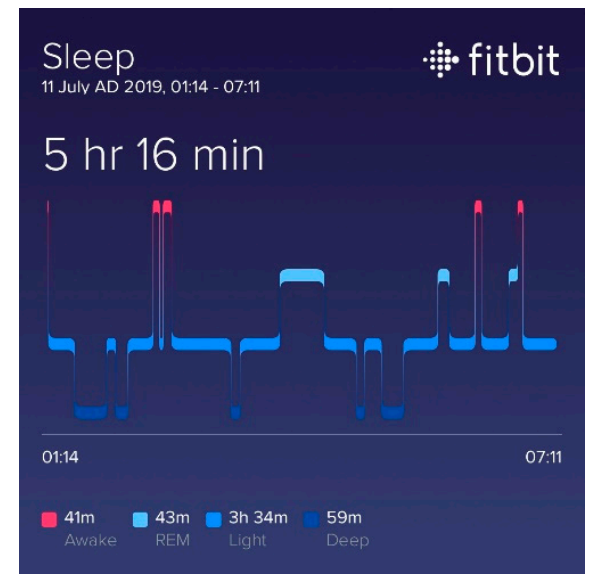

Figure A12. Bangkok, Thailand. 


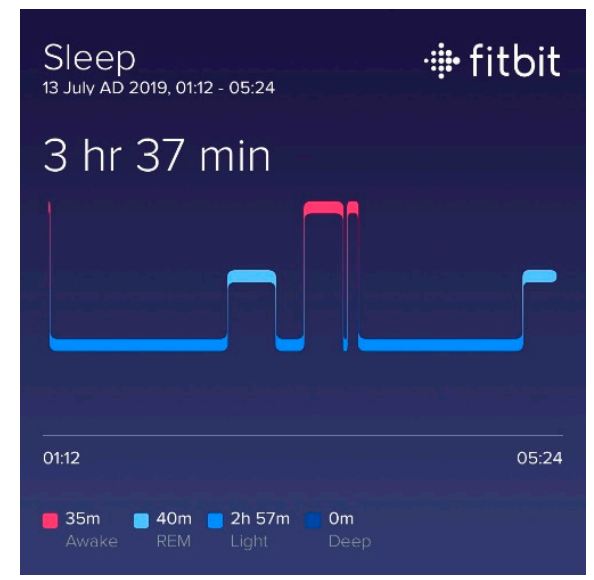

Figure A13. Hokkaido, Japan.

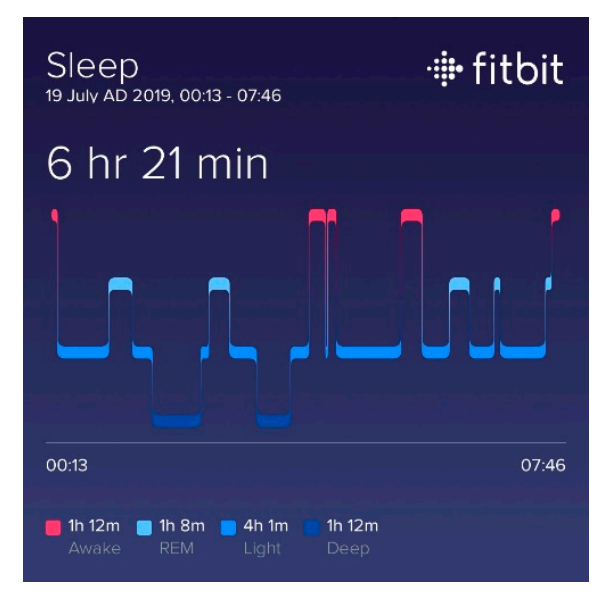

Figure A14. Shanghai, China.

Figures A15-A21 show sleep pattern of the 1st Female Flight Attendant at various sleep ports.

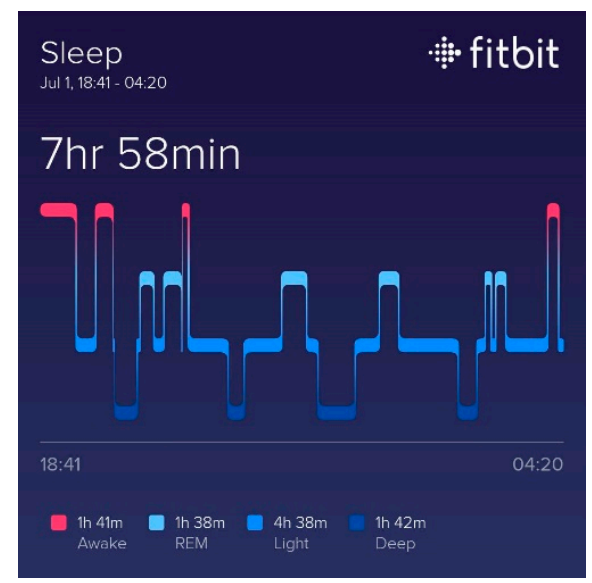

Figure A15. Copenhagen, Denmark. 


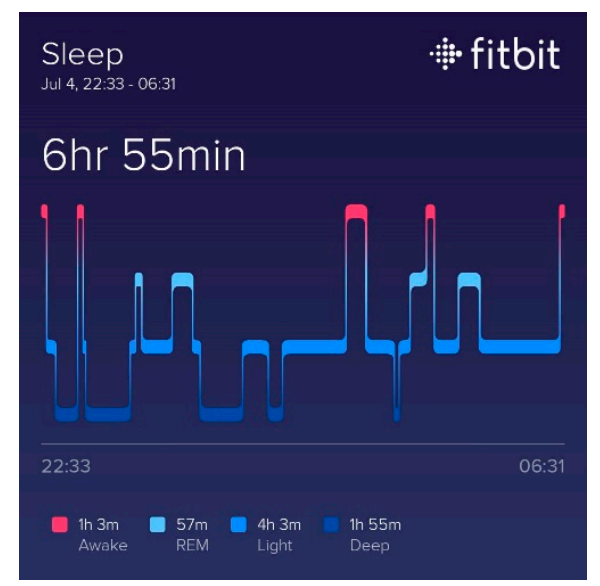

Figure A16. Sydney, Australia.

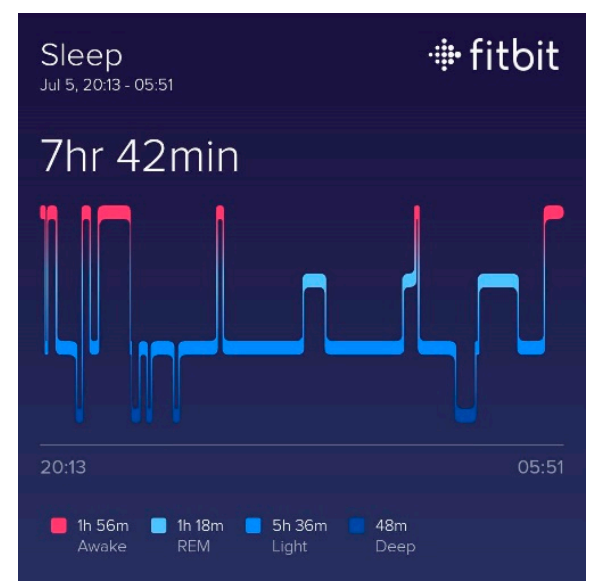

Figure A17. Bangkok, Thailand.

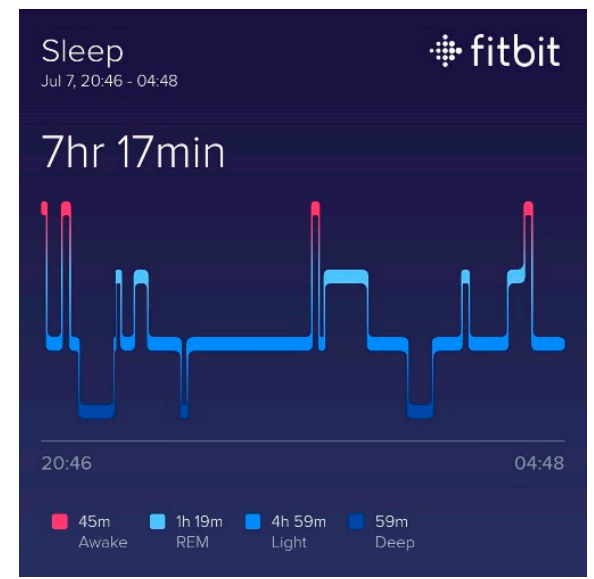

Figure A18. Saigon, Vietnam. 


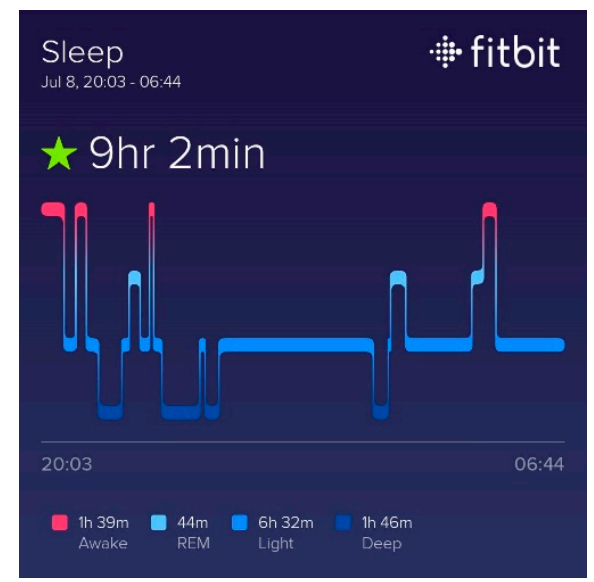

Figure A19. Bangkok, Thailand.

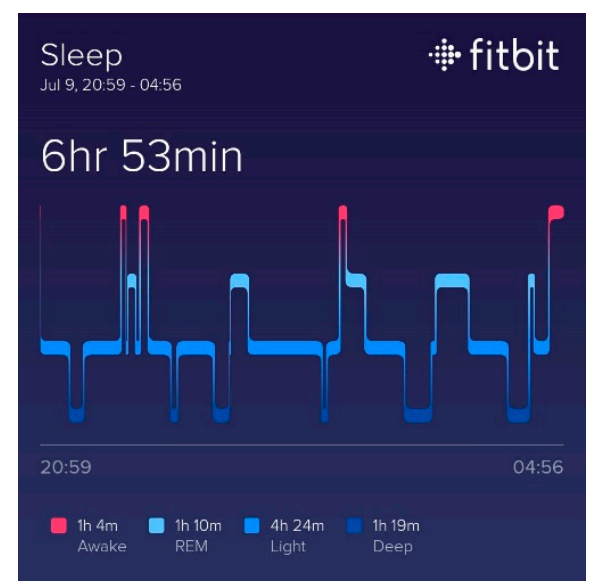

Figure A20. Hanoi, Vietnam.

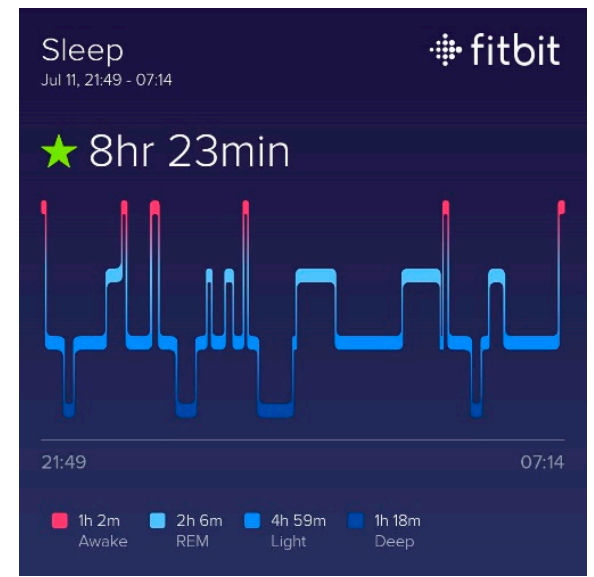

Figure A21. MUSCAT, OMAN.

Figures A22-A28 show sleep pattern of the 2nd Female Flight Attendant at various sleep ports. 


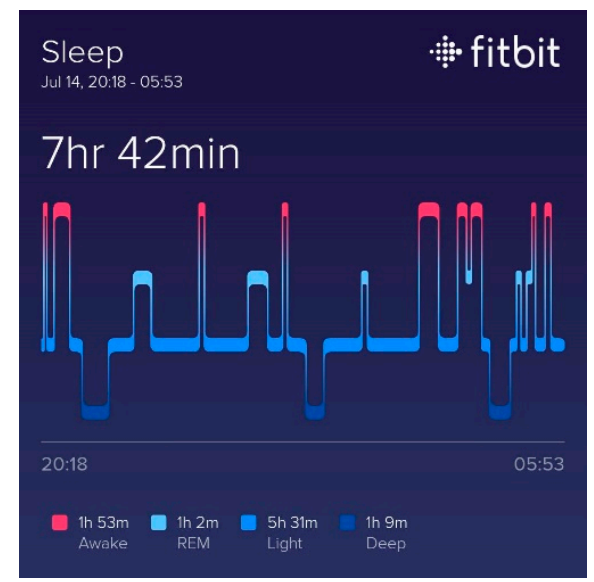

Figure A22. Chiang Mai, Thailand.

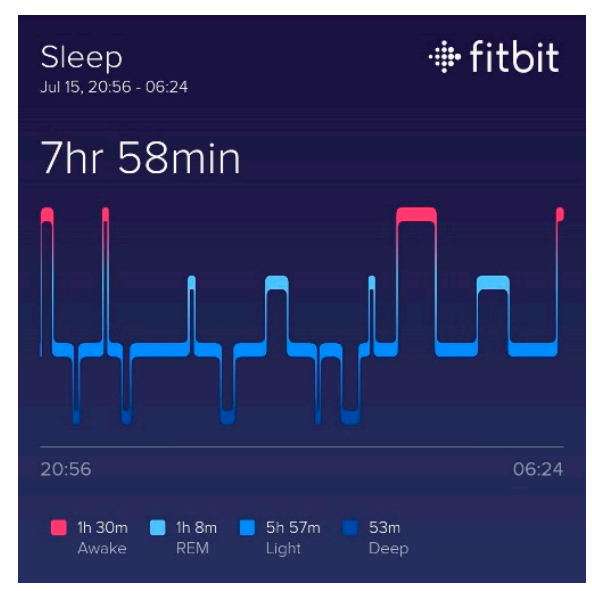

Figure A23. Phuket, Thailand.

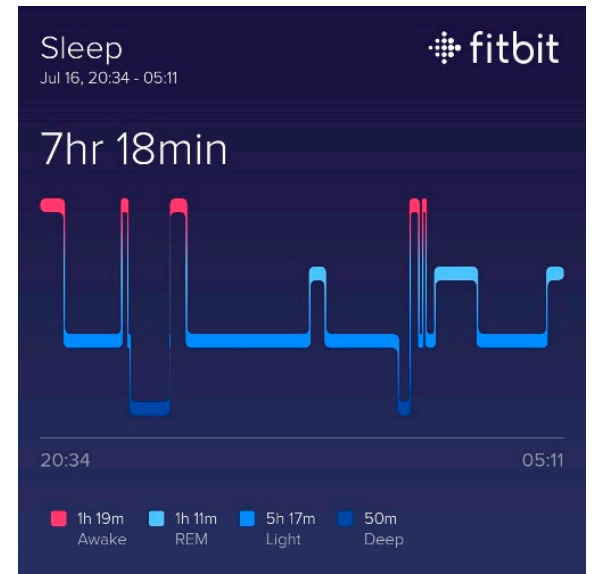

Figure A24. Bangkok, Thaiand. 


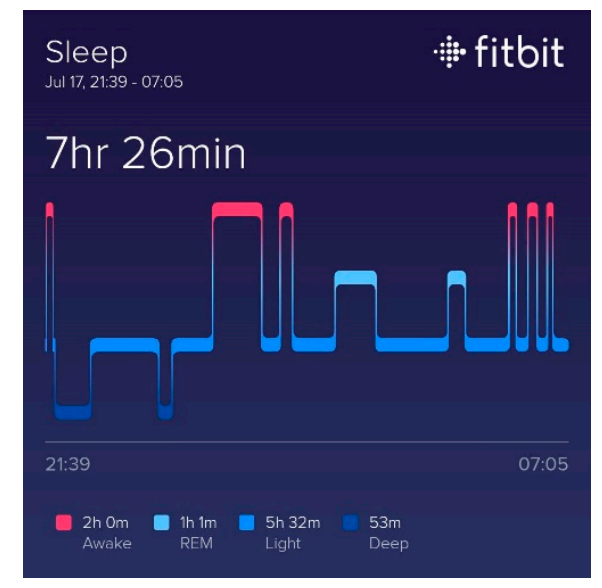

Figure A25. Dubai, UAE.

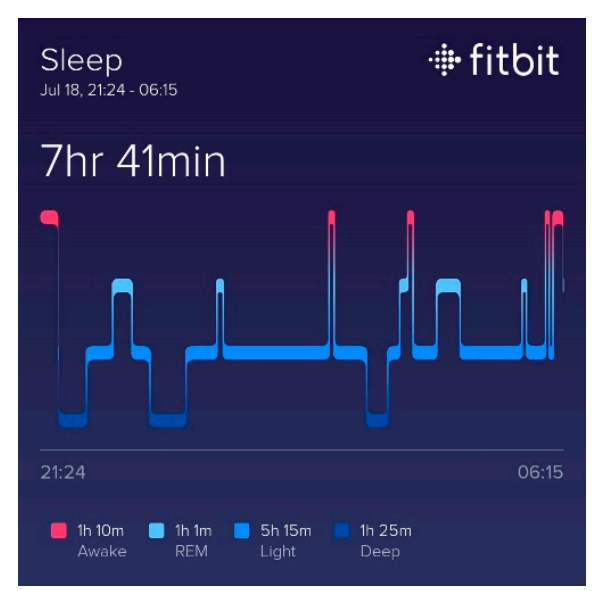

Figure A26. Dubai, UAE.

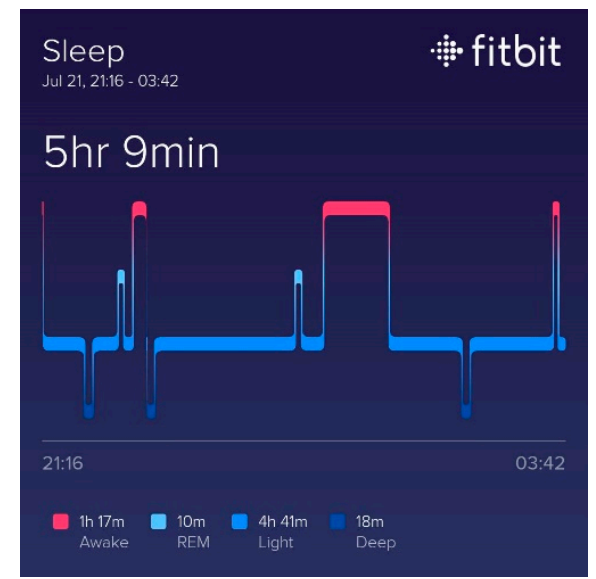

Figure A27. Bangkok, Thailand. 


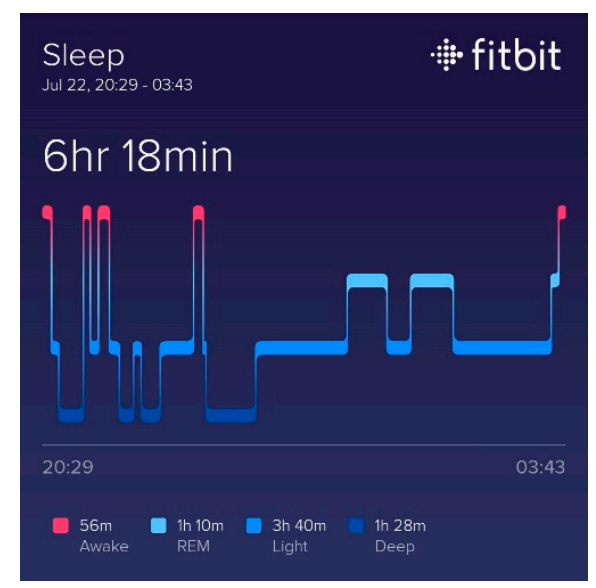

Figure A28. Taipei, Taiwan.

\section{References}

1. The Science of Sleep: Understanding What Happens When You Sleep. Available online: https://www.hopkinsmedicine.org/health/wellness-and-prevention/the-science-of-sleep-understandingwhat-happens-when-you-sleep (accessed on 28 November 2019).

2. Ezenwanne, E. Current Concepts in the Neurophysiologic Basis of Sleep: A Review. Ann. Med. Health Sci. Res. 2011, 1, 173-179.

3. A Study of Possible Sleep Deprivation in Medical Students. ResearchGate. Available online: https://www.researchgate.net/publication/315089624_A_Study_of_Possible_Sleep_Deprivation_in_Medic al_Students (accessed on 28 November 2019).

4. Ashu, D. Sleep Disorder: Aetiology and Management. Indian J. Health Wellbeing 2016, 7, 266.

5. Natural Patterns of Sleep I Healthy Sleep. Available online: http://healthysleep.med.harvard.edu/healthy/ science/what/sleep-patterns-rem-nrem. (accessed on 3 December 2019).

6. Buysse, D.J.; Reynolds, C.F.; Monk, T.H.; Berman, S.R.; Kupfer, D.J. The Pittsburgh Sleep Quality Index: A new instrument for psychiatric practice and research. Psychiatry Res. 1989, 28, 193-213, doi:10.1016/01651781(89)90047-4.

7. Purves, D.; Augustine, G.J.; Fitzpatrick, D.; Hall, W.C.; Lamantia, A.-S.; McNamara, J.O. The Circadian Cycle of Sleep and Wakefulness. In Neuroscience, 2nd ed.; Sinauer Associates: Sunderland, MA, USA, 2001. Available online: https://www.ncbi.nlm.nih.gov/books/NBK10839/ (accessed on 28 November 2019).

8. Purves, D.; Augustine, G.J.; Fitzpatrick, D.; Hall, W.C.; Lamantia, A.-S.; McNamara, J.O. (Eds.) Stages of Sleep. In Neuroscience, 2nd ed.; Sinauer Associates: Sunderland, MA, USA, 2001. Available online: https://www.ncbi.nlm.nih.gov/books/NBK10996/ (accessed on 28 November 2019).

9. Purves, D.; Augustine, G.J.; Fitzpatrick, D.; Hall, W.C.; Lamantia, A.-S.; McNamara, J.O. (Eds.) Physiological Changes in Sleep States. NIn Neuroscience, 2nd ed.; Sinauer Associates: Sunderland, MA, USA, 2001. Available online: https://www.ncbi.nlm.nih.gov/books/NBK10916/ (accessed on 28 November 2019).

10. Burkhalter, T.M.; Hillman, C.H. A narrative review of physical activity, nutrition, and obesity to cognition and scholastic performance across the human lifespan. Adv. Nutr. 2011, 2, 201S-206S, doi:10.3945/an.111.000331.

11. Bush, A.L.; Armento, M.E.; Weiss, B.J.; Rhoades, H.M.; Novy, D.M.; Wilson, N.L.; Kunik, M.E.; Stanley, M.A. The Pittsburgh Sleep Quality Index in older primary care patients with generalized anxiety disorder: Psychometrics and outcomes following cognitive behavioral therapy. Psychiatry Res. 2012, 199, 24-30, doi:10.1016/j.psychres.2012.03.045.

12. Otte, J.L.; Rand, K.L.; Carpenter, J.S.; Russell, K.M.; Champion, V.L. Factor analysis of the Pittsburgh Sleep Quality Index in breast cancer survivors. J. Pain Symptom Manag. 2013, 45, 620-627, doi:10.1016/j.jpainsymman.2012.03.008.

13. Yang, C.-M.; Wu, C.-H.; Hsieh, M.-H.; Liu, M.-H.; Lu, F.-H. Coping with sleep disturbances among young adults: A survey of first-year college students in Taiwan. Behav. Med. 2003, 29, 133-138, doi:10.1080/08964280309596066. 
14. Cole, J.C.; Motivala, S.J.; Buysse, D.J.; Oxman, M.N.; Levin, M.J.; Irwin, M.R. Validation of a 3-Factor Scoring Model for the Pittsburgh Sleep Quality Index in Older Adults. Sleep 2006, 29, 112-116, doi:10.1093/sleep/29.1.112.

15. O'Brien, E.M.; Mindell, J.A. Sleep and Risk-Taking Behavior in Adolescents. Behav. Sleep Med. 2005, 3, 113133, doi:10.1207/s15402010bsm0303_1.

16. Mollaoglu, H.; Ucok, K.; Kaplan, A.; Genc, A.; Mayda, H.; Guzel, H.I.; Sener, U.; Uygur, E.; Ozbulut, O. Association analyses of depression, anxiety, and physical fitness parameters in Turkish obese adults. J. Back Musculoskelet. Rehabil. 2012, 25, 253-260, doi:10.3233/BMR-2012-0333.

17. Tzeng, J.I.; Fu, Y.-W.; Lin, C.-C. Validity and reliability of the Taiwanese version of the Pittsburgh Sleep Quality Index in cancer patients. Int. J. Nurs. Stud. 2012, 49, 102-108, doi:10.1016/j.ijnurstu.2011.08.004.

18. Curcio, G.; Tempesta, D.; Scarlata, S.; Marzano, C.; Moroni, F.; Rossini, P.M.; Ferrara, M.; De Gennaro, L. Validity of the Italian Version of the Pittsburgh Sleep Quality Index (PSQI). Neurol. Sci. 2013, 34, 511-519, doi:10.1007/s10072-012-1085-y.

19. Hashmi, A.M.; Khawaja, I.S.; Butt, Z.; Umair, M.; Naqvi, S.H.; Ul-Haq, J. The Pittsburgh Sleep Quality Index: Validation of the Urdu translation. J. Coll. Physicians Surg. Pak. 2014, 24, 123-126, doi:02.2014/JCPSP.123126.

20. Ho, R.T.H.; Fong, T.C.T. Factor structure of the Chinese version of the Pittsburgh Sleep Quality Index in breast cancer patients. Sleep Med. 2014, 15, 565-569, doi:10.1016/j.sleep.2013.10.019.

21. Guo, S.; Sun, W.; Liu, C.; Wu, S. Structural validity of the Pittsburgh Sleep Quality Index in Chinese undergraduate students. Front. Psychol. 2016, 7, doi:10.3389/fpsyg.2016.01126.

22. Griffiths, R.F.; Powell, D.M.C. The occupational health and safety of flight attendants. Aviat. Space Environ. Med. 2012, 83, 514-521, doi:10.3357/asem.3186.2012.

23. Banks, S.; Dinges, D.F. Behavioral and Physiological Consequences of Sleep Restriction. J. Clin. Sleep Med. 2007, 3, 519-528.

24. Ford, E.S.; Cunningham, T.J.; Croft, J.B. Trends in Self-Reported Sleep Duration among US Adults from 1985 to 2012. Sleep 2015, 38, 829-832, doi:10.5665/sleep.4684.

25. Consensus Conference Panel; Watson, N.F.; Badr, M.S.; Belenky, G.; Bliwise, D.L.; Buxton, O.M.; Buysse, D.; Dinges, D.F.; Gangwisch, J.; Grandner, M.A.; et al. Joint Consensus Statement of the American Academy of Sleep Medicine and Sleep Research Society on the Recommended Amount of Sleep for a Healthy Adult: Methodology and Discussion. Sleep 2015, 38, 1161-1183, doi:10.5665/sleep.4886.

26. Watson, N.F.; Badr, M.S.; Belenky, G.; Bliwise, D.L.; Buxton, O.M.; Buysse, D.; Dinges, D.F.; Gangwisch, J.; Grandner, M.A.; Kushida, C. Recommended Amount of Sleep for a Healthy Adult: A Joint Consensus Statement of the American Academy of Sleep Medicine and Sleep Research Society. Sleep 2015, 38, 843-844, doi:10.5665/sleep.4716.

27. McKnight-Eily, L.R.; Liu, Y.; Perry, G.S.; Presley-Cantrell, L.R.; Strine, T.W.; Lu, H.; Croft, J.B. Perceived insufficient rest or sleep among adults-United States, 2009. J. Am. Med. Assoc. 2009, 302, 2532.

28. Punjabi, N.M.; Bandeen-Roche, K.; Young, T. Predictors of objective sleep tendency in the general population. Sleep 2003, 26, 678-683, doi:10.1093/sleep/26.6.678.

29. Abe, T.; Komada, Y.; Inoue, Y. Short sleep duration, snoring and subjective sleep insufficiency are independent factors associated with both falling asleep and feeling sleepiness while driving. Int. Med. 2012, 51, 3253-3260, doi:10.2169/internalmedicine.51.7518.

30. Sciences, S.; Board, T.R.; National Academies of Sciences, Engineering, and Medicine. Consequences of Fatigue from Insufficient Sleep; National Academies Press: Washington, DC, USA, 2016. Available online: https://www.ncbi.nlm.nih.gov/books/NBK384963/ (accessed on 29 November 2019).

31. Scott, L.D.; Hwang, W.-T.; Rogers, A.E.; Nysse, T.; Dean, G.E.; Dinges, D.F. The Relationship between Nurse Work Schedules, Sleep Duration, and Drowsy Driving. Sleep 2007, 30, 1801-1807.

32. Panel on Research Methodologies and Statistical Approaches to Understanding Driver Fatigue Factors in Motor Carrier Safety and Driver Health; The National Academies Press: Washington, DC, USA. Available online: https://www.nap.edu/initiative/panel-on-research-methodologies-and-statistical-approaches-tounderstanding-driver-fatigue-factors-in-motor-carrier-safety-and-driver-health (accessed on 29 November 2019).

33. Slater, G.; Steier, J. Excessive daytime sleepiness in sleep disorders. J. Thorac. Dis. 2012, 4, 608-616, doi:10.3978/j.issn.2072-1439.2012.10.07. 
34. Fatigue in Aviation: A Survey of the Awareness and Attitudes of Indian Air Force Pilots; Request PDF; ResearchGate. Available online: https:/www.researchgate.net/publication/254304312_Fatigue_in_ Aviation_A_Survey_of_the_Awareness_and_Attitudes_of_Indian_Air_Force_Pilots (accessed on 29 November 2019).

35. Potter, G.D.M.; Skene, D.J.; Arendt, J.; Cade, J.E.; Grant, P.J.; Hardie, L.J. Circadian Rhythm and Sleep Disruption: Causes, Metabolic Consequences, and Countermeasures. Endocr. Rev. 2016, 37, 584-608, doi:10.1210/er.2016-1083.

36. Venter, R.E. Role of sleep in Performance and Recovery of Athletes: A Review Article. Available online: https://www.ingentaconnect.com/content/sabinet/sport/2012/00000034/00000001/art00012 (accessed on 1 January 2012).

37. Orzeł-Gryglewska, J. Consequences of sleep deprivation. Int. J. Occup. Med. Environ. Health 2010, 23, 95114, doi:10.2478/v10001-010-0004-9.

38. Baglioni, C.; Nanovska, S.; Regen, W.; Spiegelhalder, K.; Feige, B.; Nissen, C.; Reynolds, I.I.I.C.F.; Riemann, D. Sleep and mental disorders: A meta-analysis of polysomnographic research. Psychol. Bull. 2016, 142, 969 990, doi:10.1037/bul0000053.

39. Escobar-Córdoba, F.; Quijano-Serrano, M.; Calvo-González, J.M. Evaluation of insomnia as a risk factor for suicide. Revista de la Facultad de Ciencias Medicas 2017, 74, 37-45.

(C) 2019 by the authors. Licensee MDPI, Basel, Switzerland. This article is an open access article distributed under the terms and conditions of the Creative Commons Attribution (CC BY) license (http://creativecommons.org/licenses/by/4.0/). 